\title{
Ocular morphology of the fruit bat, Eidolon helvum, and the optical role of the choroidal papillae in the megachiropteran eye: a novel insight
}

\author{
I.K. Peter-Ajuzie1, I.C. Nwaogu1', L.O. Majesty-Alukagberie², A.C. Ajaebili1', F.A. Farrag³, \\ M.A. Kassab" , K. Morsy, ${ }^{5}$, M. Abumandour ${ }^{7}$ \\ ${ }^{1}$ Department of Veterinary Anatomy, Faculty of Veterinary Medicine, University of Nigeria, Nsukka, Enugu State, Nigeria \\ ${ }^{2}$ Department of Veterinary Public Health and Preventive Medicine, Faculty of Veterinary Medicine, University of Nigeria, \\ Nsukka, Enugu State, Nigeria \\ ${ }^{3}$ Department of Anatomy and Embryology, Faculty of Veterinary Medicine, Kafrelsheikh University, Kafrelsheikh, Egypt \\ ${ }^{4}$ Department of Cytology and Histology, Faculty of Veterinary Medicine, Kafrelsheikh University, Kafrelsheikh, Egypt \\ ${ }^{5}$ Biology Department, College of Science, King Khalid University, Abha, Saudi Arabia \\ ${ }^{6}$ Zoology Department, Faculty of Science, Cairo University, Cairo, Egypt \\ ${ }^{7}$ Department of Anatomy and Embryology, Faculty of Veterinary Medicine, Alexandria University, Alexandria, Egypt
}

[Received: 26 June 2021; Accepted: 8 July 2021; Early publication date: 21 July 2021]

Background: This work was designed to provide a morphologic, morphometric and histochemical description of the eye of the African straw-coloured fruit bat (Eidolon helvum). An explanation of the optical role of the choroidal papillae in the vision of megachiropteran bats was provided.

Materials and methods: Enucleated eyes of captured fruit bats were measured and processed for light microscopy.

Results: Typical gross features of the mammalian eye including an anterior transparent cornea, posterior whitish sclera and a golden-brown iris surrounding a round pupil were observed in the eye. Presence of undulating retina typically found in megachiropterans was also seen. The ratio of mean corneal diameter to mean axial eye diameter was $0.58 \pm 0.08$. The histochemical investigation of the eye indicated the presence of mucins, proteoglycans, hyaluronic acid, glycogen and/or glycoproteins in the corneal, scleral, choroidal and retinal tissues.

Conclusions: The presence of reflective materials of the tapetum lucidum on the undulating retina was shown to be a morphological adaptation for increased light sensitivity as each parabolic surface of the choroidal papillae served as a convex mirror, reflecting the light rays to the adjacent parabolic surface, thus sensitising photoreceptors in affected regions. This phenomenon thus empowers megachiropteran bats with improved scotopic visual capability and could explain why most of them are reliant on their vison without the need for echolocation. (Folia Morphol 2022; 81, 3: 715-722)

Key words: Eidolon helvum, eye, choroidal papillae, retina, megachiroptera 


\section{INTRODUCTION}

The eye of an organism enables it to perceive the myriad of emitted and reflected light rays in its environment. This perception is required for the survival of the organism especially during its periods of peak activity. The activity pattern of an animal is therefore related to its ocular morphological characteristics and has been reported by many ocular scientists [1, 10, 16-19, 22, 23, 32, 33].

The African straw-coloured fruit bat, Eidolon helvum, is a megabat that is widely distributed in sub-Saharan Africa [3]. The bats are nocturnal, live in large colonies, and can be found roosting on trees close to human habitation [27]. Some African communities use these bats for certain ritual purposes. Their frugivorous, arboreal and migratory nature enables them to function in plant pollination and plant geographical distribution [30]. The species has been identified as a natural reservoir of a number of zoonotic viral diseases such as those caused by the Ebola subtype Zaire and Lagos bat viruses [3]. Their close proximity and association with humans create a need for a comprehensive body of knowledge on their biology especially since they have been associated with some epidemics. This study therefore investigated the morphological features of the eyes of this species which were hitherto scarce in literature in order to expound its ocular biology and determine any relationship between its ocular characteristics and activity pattern. It also provided an explanation on the role of the choroidal papillae in the vision of megachiropterans which hitherto had been a subject of controversy among scientists. The results of this study might be helpful in the recognition of ocular pathology in this species and related species and in the determination of its corneal xenotransplantation potential in humans as well as the possible application of the eye morphology in technology.

\section{MATERIALS AND METHODS}

\section{Sample collection}

No animals were killed exclusively for this study. The 6 bats ( 3 males and 3 females) with mean body weight of $247.44 \pm 45.77 \mathrm{~g}$ used for this study were part of the experimental animals approved by the Institutional Animal Care and Use Committee of the Faculty of Veterinary Medicine, University of Nigeria, Nsukka (Approval number: FVMUNN-IACUC-2019-0350) for the PhD studies of Dr. L.O. Obodoechi of the Department of Veterinary Public Health and Preventive Medicine, Faculty of Veterinary Medicine, University of
Nigeria. Dr. Obodoechi needed only the brain sample of the captured animals for her PhD studies while the eye samples were obtained for this study. The animals were reportedly captured from the wild between January and February in Obiagu, Awgu L.G.A., Enugu State, Nigeria. Following euthanasia of the bats using $50 \mathrm{mg} /$ $\mathrm{kg}$ ketamine hydrochloride, horizontal and vertical corneal diameters were obtained from each eye using Vernier calliper. Eyes were bilaterally enucleated [17], and the horizontal, vertical, and axial eye diameters were obtained as well as its gross anatomical and topographical characteristics.

\section{Histology}

Whole enucleated eyes were fixed in Davidson's fixative [2] for 18 hours and postfixed in $10 \%$ neutral buffered formalin. They were subsequently dehydrated in increasing concentrations of ethanol, cleared in xylene, infiltrated with paraffin and embedded in paraffin blocks. Five $\mu \mathrm{m}$ thick meridional sections were cut, mounted on glass slides, and routinely stained with haematoxylin and eosin (H\&E) [7], Masson's trichrome [6] and Periodic Acid-Schiff-Alcian Blue (PAS-AB) $(\mathrm{pH} 2.5)$ [26] stains. Photomicrographs were captured using Moticam Images Plus 2.0 digital camera (Motic China Group Ltd., China). Corneal and retinal thicknesses were measured using the camera software.

\section{Statistical analysis}

Data were analysed using SPSS Statistics 17.0 software. Mean corneal diameter was taken as the mean of the horizontal and vertical corneal diameters while mean eye diameter was taken as the mean of the horizontal and vertical eye diameters. Data were presented as mean \pm standard deviation. Data was tested for normality and paired samples t-test statistic (2-tailed) was used to determine any significant differences between the axial and horizontal eye diameters, vertical and horizontal eye diameters, vertical and axial eye diameters, and vertical and horizontal corneal diameters. Statistical significance was accepted at $p<0.05$.

\section{RESULTS}

\section{Gross anatomy}

The eyes were located dorsolaterally in the orbital cavities of the skull and were separated by a flat frontal region (Fig. 1). They exhibited typical gross features of the mammalian eye including an anterior transparent cornea and a posterior whitish sclera as 


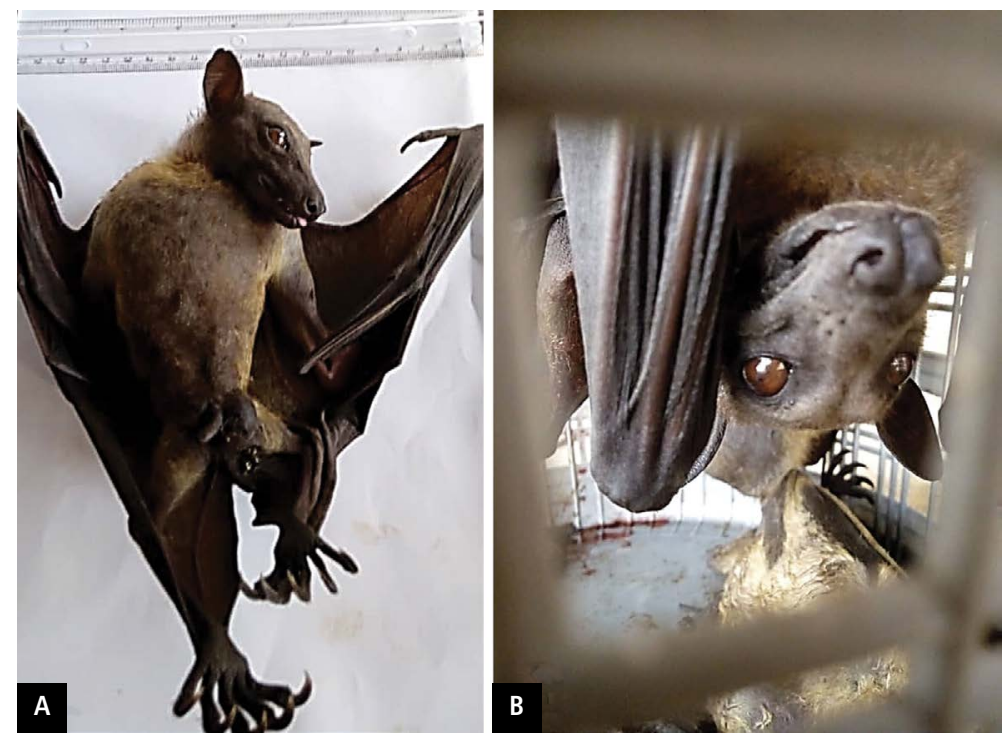

Figure 1. A. The African straw-coloured fruit bat showing the dorsolaterally-located eyes separated by a flat frontal region; B. The golden-brown-coloured iris is visible through its transparent cornea as the bat hangs upside down in the cage. well as a golden-brown iris surrounding a round pupil which were visible through the cornea.

The vertical and horizontal corneal diameters were $0.57 \pm 0.10 \mathrm{~cm}$ and $0.56 \pm 0.10 \mathrm{~cm}$, respectively $(n=12)$. Both diameters were not significantly different $(p<0.05)$ from each other. The vertical, horizontal and axial eye diameters were $0.98 \pm 0.10 \mathrm{~cm}, 0.99 \pm 0.11 \mathrm{~cm}$ and $0.98 \pm 0.06 \mathrm{~cm}$, respectively $(\mathrm{n}=12)$. They were also not significantly different $(p<0.05)$ from each other. The ratio of mean corneal diameter to mean eye diameter was $0.58 \pm 0.09(n=12$; range: $0.42-0.70)$ while the ratio of mean corneal diameter to mean axial eye diameter was $0.58 \pm 0.08(n=12$; range: $0.43-0.72)$.

\section{Histology}

Fibrous tunic. The cornea was lined anteriorly by non-keratinised stratified squamous corneal epithelium and posteriorly by simple squamous corneal endothelium, between which was dense regular fibrous connective tissue of the corneal stroma (Fig. 2). The basement membrane of the corneal endothelium known as the Descemet's membrane was thicker than that of the corneal epithelium. Both membranes were strongly PAS-positive while the corneal stroma which was bluish purple in colour was PAS-AB-positive. The sclera was a dense irregular fibrous connective tissue (Fig. 3). Its numerous collagen fibres were continuous with those of the corneal stroma.

Uvea. The iris was a heavily pigmented and vascularised tissue process that was attached to the ciliary body (Fig. 4B). The ciliary body which did not seem well-developed comprised a posterior pars plana and anterior ciliary processes (or pars plicata) both of which were composed of ciliary epithelia overlying ciliary stroma (Fig. 4A, C). The ciliary epithelia comprised an outer pigmented epithelium and an inner non-pigmented simple cuboidal epithelium. The epithelia were continuous with the retina at the ora serrata. The vascularised pigmented choroid lay between the retina and the sclera. Its numerous projections, the choroidal papillae, projected markedly perpendicularly or obliquely towards the retina in the direction of the pupil (Figs. 3-5). These papillae caused undulations in the retinal tissues.

Retina. Undulating outer layers and non-undulating inner layers were observed in the retina (Fig. 3). The undulating layers comprised the retinal epithelium, photoreceptor layer, outer nuclear layer and outer plexiform layer while the non-undulating layers comprised the inner nuclear layer, inner plexiform layer, ganglion cells and nerve axons (Fig. 5). Some areas of the retina especially towards the ora serrata where choroidal papillae were absent lacked these retinal undulations (Fig. 5D). The photoreceptor layer was AB-positive and was composed of photoreceptor outer segment and photoreceptor inner segment. The outer segment was more deeply $A B$-positive than the inner segment while the outer and inner plexiform layers were weakly $A B$-positive (Fig. 5C). The retinal epithelium, inner nuclear layer and ganglion cell layers were weakly PAS-AB-positive. The retinal epithelium was simple cuboidal epithelium containing pigmented or non-pigmented mononuclear cells with basally-located nuclei and clear cytoplasm. It was tightly attached to the choroid, following all of its undulating contours. From the ora 


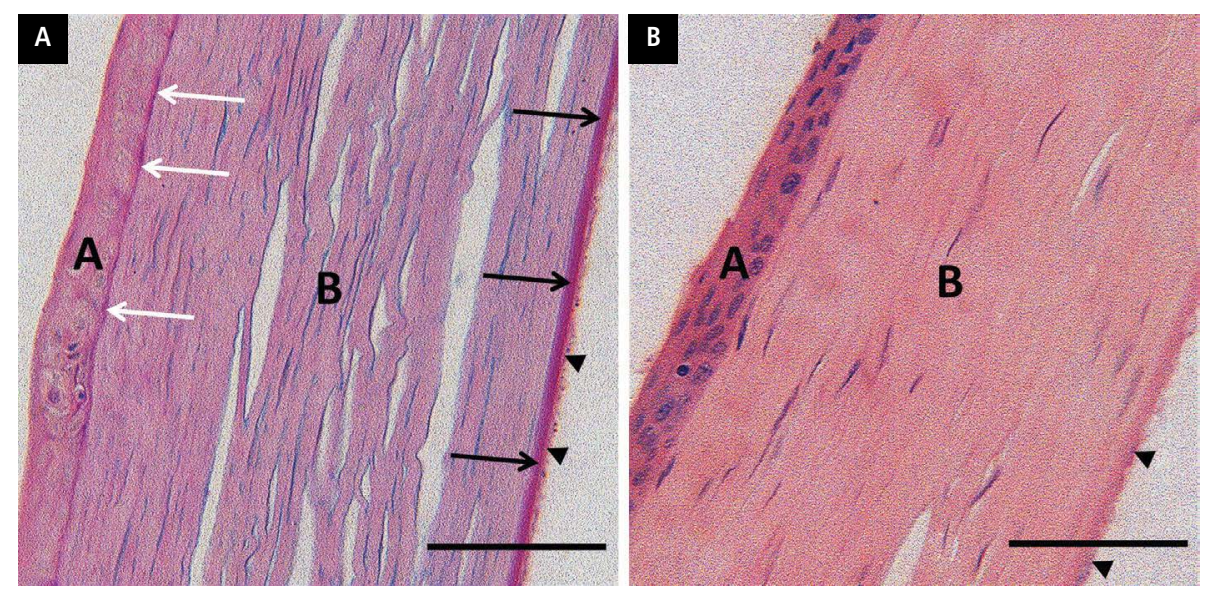

Figure 2. Photomicrographs of the cornea of the African straw-coloured fruit bat stained with Periodic Acid Schiff (PAS)-Alcian Blue stain at $\mathrm{pH} 2.5$ (A) and haematoxylin and eosin (B). Corneal epithelium (A) with its thin PAS positive basement membrane (white arrows), corneal stroma (B), corneal endothelium (arrow heads) with its thick PAS-positive Descemet's membrane (black arrows); scale bars $=50 \mu \mathrm{m}$.
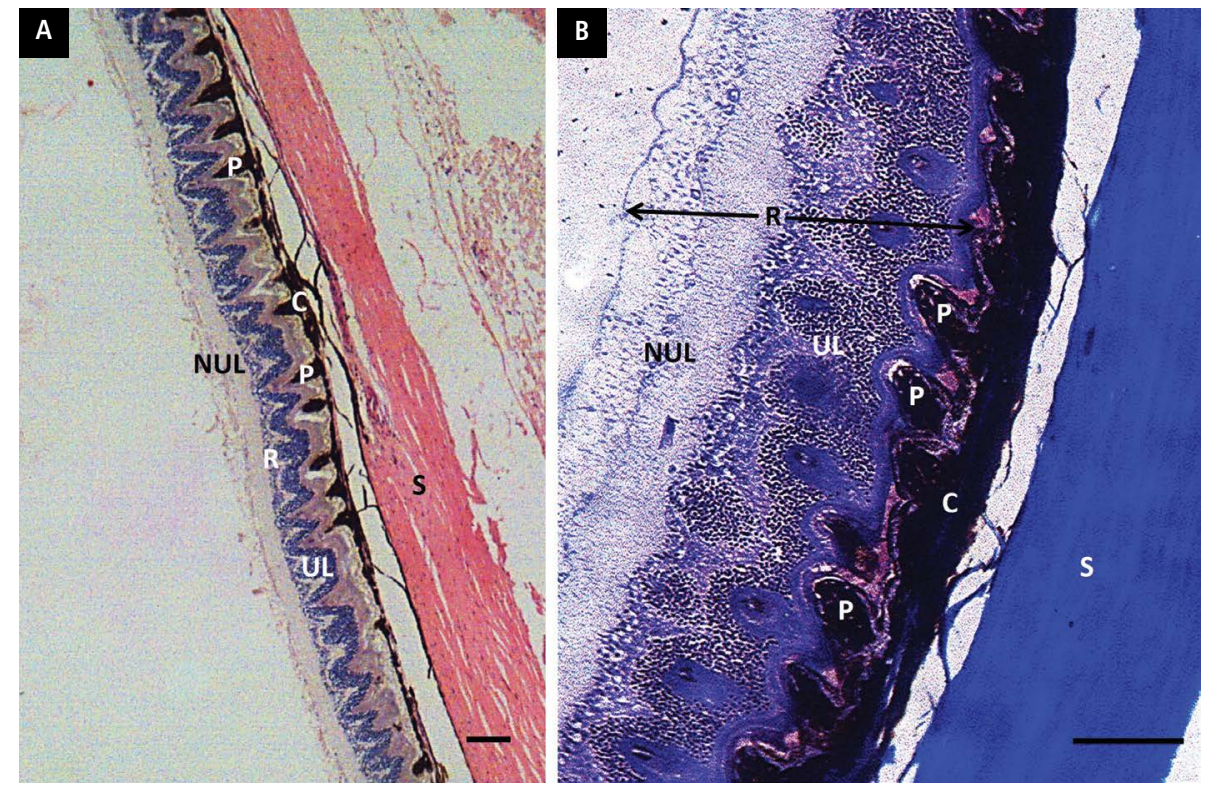

Figure 3. Photomicrographs of the eye of the African straw-coloured fruit bat stained with haematoxylin and eosin (A) and Masson's trichrome (B). Sclera (S), choroid (C) with its choroidal papillae (P), retina (R) with its undulating (UL) and non-undulating (NUL) layers; scale bars $=100 \mu \mathrm{m}$.

serrata to the posterior pole, the pigmented retinal epithelium gradually lost its apical melanin pigments such that towards the posterior pole, the epithelium lacked pigments. The nuclei of the photoreceptor cells in the outer nuclear layer were heterochromatic unlike the nuclei in the outer nuclear and ganglion cell layers which were euchromatic.

\section{DISCUSSION AND CONCLUSIONS}

\section{Histochemistry}

The PAS-AB histochemical stain which is used for the detection of some categories of carbohydrates and glycoconjugates was employed in this study to determine if the carbohydrate composition of the fruit bat eye was similar to those reported for other animals. The PAS-AB histochemical reactions indicated the presence of glycoproteins, proteoglycans, hyaluronic acid and/or glycogen in the corneal, scleral, choroidal and retinal tissues [26]. Different shades of blue colouration as seen in the inner and outer segments of the photoreceptor layer as well as in the outer and inner plexiform layers of the retina indicated a positive $A B$ reaction which affirmed the presence of acid mucins, proteoglycans and/or hya- 

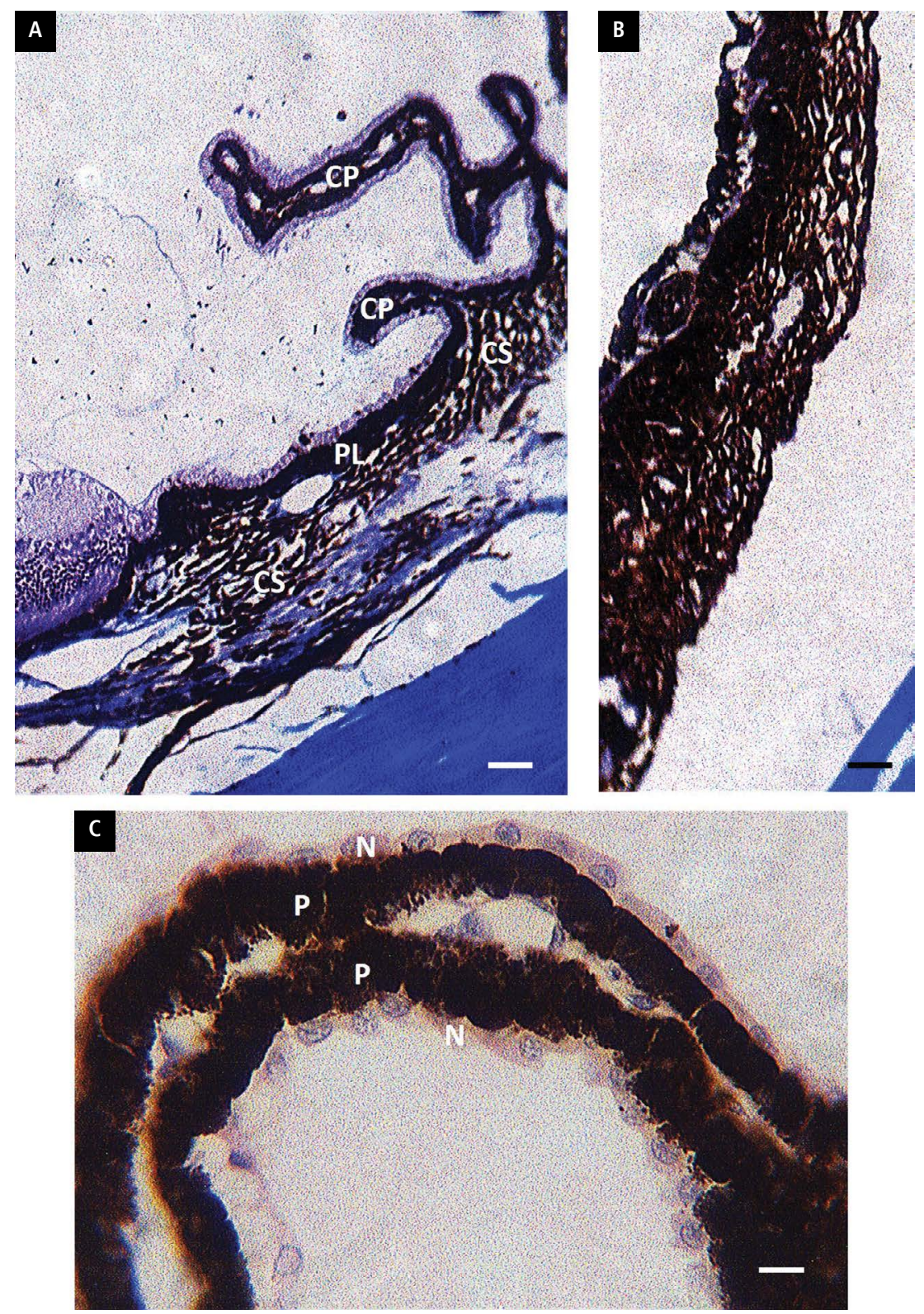

Figure 4. Photomicrographs of the ciliary body $(\mathbf{A})$, iris $(\mathbf{B})$ and ciliary process $(\mathbf{C})$ of the African straw-coloured fruit bat; $\mathrm{CP}$ - ciliary process; PL — pars plana; CS — ciliary stroma; $\mathrm{N}$ - non-pigmented epithelium; $\mathrm{P}$ - pigmented epithelium. Scale bar and stain for panels $\mathrm{A}$ and $\mathrm{B}=100 \mu \mathrm{m}$, Masson's trichrome. Scale bar and stain for panel $\mathrm{C}=10 \mu \mathrm{m}$, haematoxylin and eosin.

luronic acid in those regions of the retina. Magenta colour as seen in the Descemet's membrane and basement membrane of the corneal epithelium indicated a positive PAS reaction which affirmed the presence of glycogen and/or glycoproteins in the corneal membranes. The different shades of bluish purple colouration observed in the corneal stroma, sclera, choroid, retinal epithelium, inner nuclear layer and ganglion cell layer indicated positive reactions to both $A B$ and PAS. The blue colouration of the nuclei in the outer nuclear layer of the retina was a result of the haematoxylin counterstain used for the PAS-AB staining procedure.

Online literature search on Google Scholar (www. scholar.google.com) using different keywords showed the absence of published work on the histochemical detection of glycoproteins, proteoglycans, hyaluronic acid or glycogen in the eye of bat as at the time of writing this paper. This study may thus be the first scientific attempt to describe the carbohydrate composition of the chiropteran eye. Though immunohistochemical staining would have been more specific in determining 

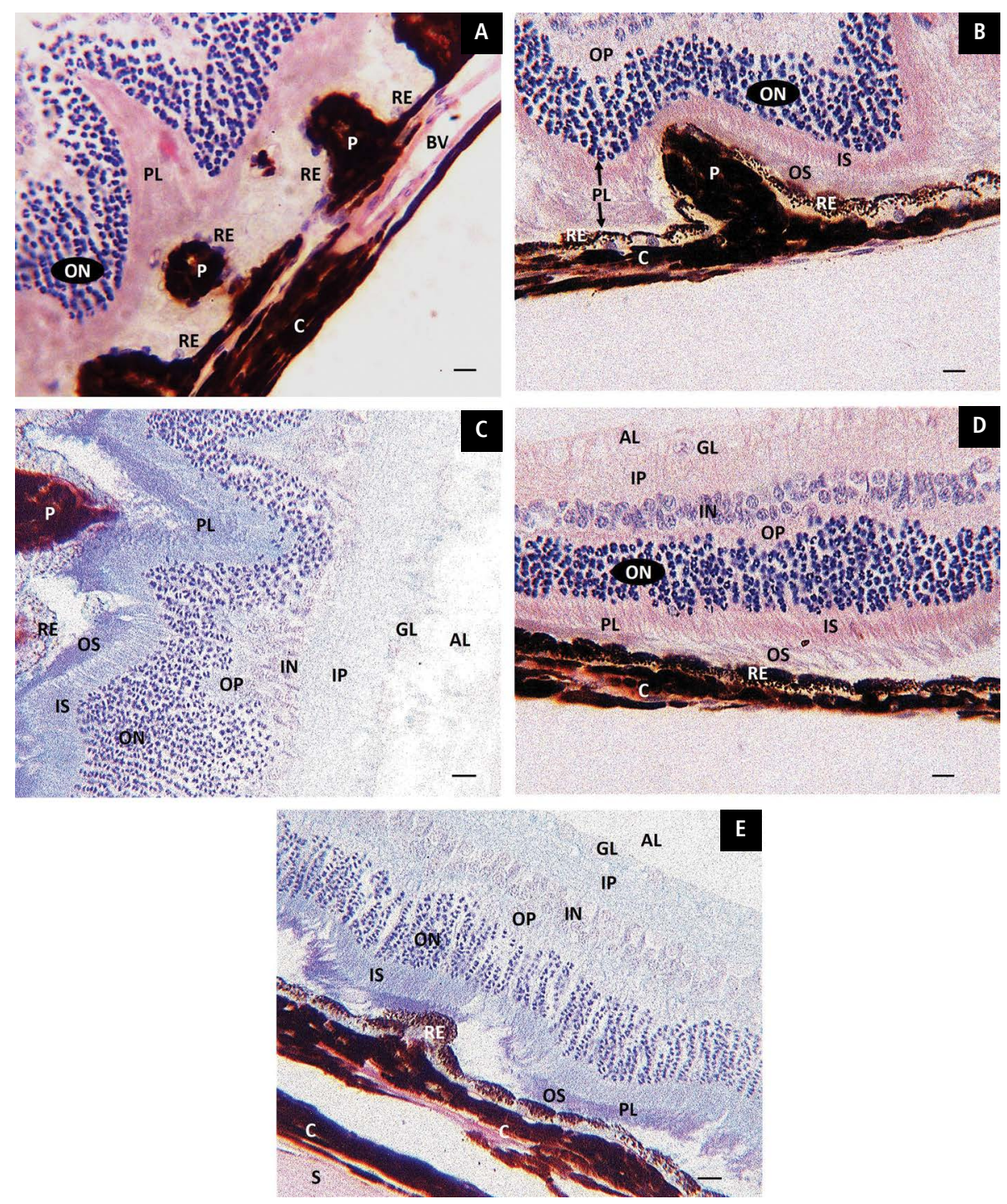

Figure 5. Photomicrographs of the retina, choroid and sclera of the African straw-coloured fruit bat. Choroidal papillae $(\mathrm{P})$ with its consequent retinal undulations are present in panels $\mathbf{A}, \mathbf{B}$ and $\mathbf{C}$; absent in panel $\mathbf{D}$ and inconspicuous in panel $\mathbf{E}$. Melanin pigments of the retinal epithelium (RE) were absent in panel $A$ but gradually increased in quantity from panel $C$ to panel $B$ to panel $E$ to panel $D$. Choroid $(C)$, blood vessel $(B V)$, photoreceptor layer (PL) comprising the inner segment (IS) and outer segment (OS), outer nuclear layer (ON), outer plexiform layer (OP), inner nuclear layer (IN), inner plexiform layer (IP), ganglion cell layer (GL), axon layer (AL), sclera (S). Haematoxylin and eosin stain (A, B and D). Periodic Acid Schiff-Alcian Blue stain, $\mathrm{pH} 2.5$ (C and E). Scale bars $=10 \mu \mathrm{m}$.

carbohydrate composition, the PAS-AB staining, however, gives a relatively general idea of the carbohydrate composition. Proteoglycans have already been isolated from retinal tissues of other mammals where they were reported to play roles in retinal neuronal growth, repairs and synapse formation [5, 20, 21]. Hyaluronic acid has been detected in the sclera, choroid and retinal pigment epithelium of humans where it was said to maintain tissue fluidity, permeation and hydration [35] as well as function in the creation of retinal neural networks through its complexes with proteoglycans [20]. Glycoproteins, which also include mucins, have been demonstrated in the cornea, sclera, ciliary body and retina of humans [15] and in the retina of cattle $[4,13]$ while glycogen which serves as cellular energy reserve has been reported in the corneal endothelium of man and rabbit [28]; retina, vitreous, lens, choroid, iris and cornea of cattle and rabbit [36]; retina of cat; corneal epithelium of rabbit [14]; and retina of guinea pig, rabbit, man, cat, cattle, hamster and fish [24].

\section{Morphometry}

The mean corneal diameter to mean axial eye diameter ratio observed in Eidolon helvum in this 
study was at variance with those reported for most nocturnal mammals and birds which have higher ratios. The ratio was rather similar to those reported for most diurnal and cathemeral animals $[16,17,23]$. The authors had postulated that the scotopic environment of nocturnal animals necessitated a higher mean corneal diameter to mean axial eye diameter ratio to enable the animals capture as much light rays as is possible from the environment while the photopic environment of diurnal animals necessitated lower ratios so as to limit the amount of light rays entering the eyes from the light-rich environment. The possession of a relatively low ratio by the nocturnal fruit bat therefore suggests that its retina has higher sensitivity to light rays than those of most nocturnal animals. Such a situation therefore eliminates the need for a high mean corneal diameter to mean axial eye diameter ratio and might provide explanations for the unusual retinal morphology of the fruit bat. In addition, the relatively low ratio could also indicate an adaptation for vision in both scotopic and photopic environments as has been reported for cathemeral animals $[16,23]$.

\section{Choroidoretinal undulations}

The unusual choroidal and retinal morphology observed in this study for Eidolon helvum have since been reported for other megachiropteran, and in particular, pteropodid bats $[1,12,25]$. The role of the choroidal papillae in blood supply to retinal tissues has been well documented $[9,11]$ but their role in vision has been a matter of controversy among scientists with some scientists asserting that the presence of the choroidal papillae led to improved visual sensitivity through an increase in the photosensitive area and number of photoreceptors [11, 31]. This assertion has, however, been refuted by Suthers [34] who clarified that the choroidal papillae couldn't lead to an increase in the photosensitive area and number of photoreceptors without a decrease in photoreceptor diameter or decrease in the space between photoreceptors or a rearrangement of the long axis of all photoreceptors to be perpendicular to the plane of undulating choroidal surface. The author, however, didn't provide an explanation for the role of the papillae in vision.

Though we did not directly check for the presence of tapetum lucidum in the Eidolon helvum, the absence of melanin pigments in the retinal epithelium of the central retina strongly suggests the existence

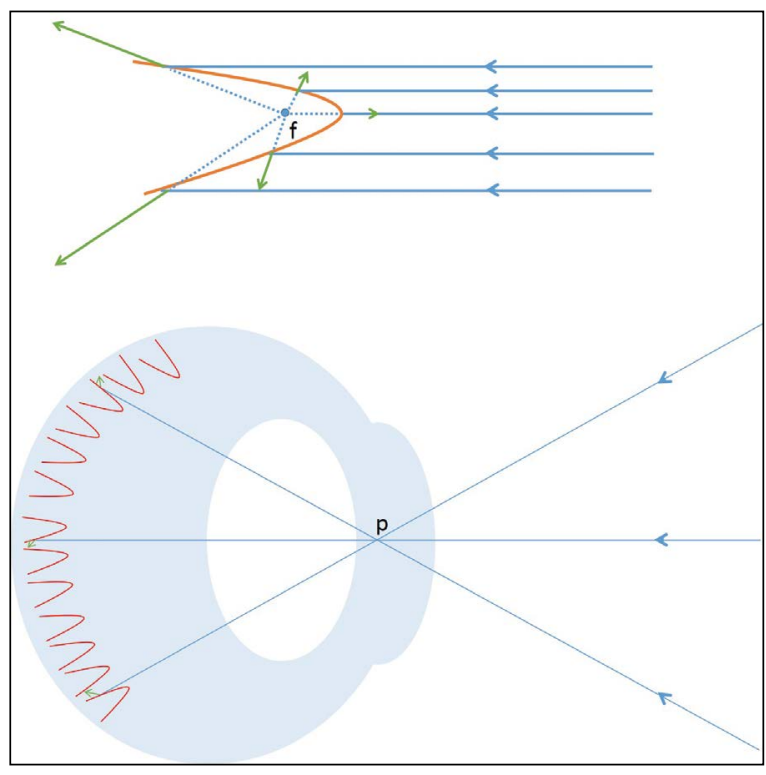

Figure 6. Schematic representation of the visual role of the choroidal papillae in the megachiropteran eye. The figure above shows a retinal tapetum lucidum-lined choroidal papilla with the incident rays (solid blue lines), reflected rays (green arrows) and the tracing of the reflected rays (dotted blue lines) from the focal point (f). The figure below shows the megachiropteran eye where incident light rays (solid blue lines) passes through the pupil ( $p$ ) to become reflected (green arrows) on hitting the retinal tapetum lucidum-lined choroidal papillae. Refraction of light rays was not taken into consideration in this schematic representation.

of tapetum lucidum in the bat. This is because the presence of tapetum lucidum in mammals is generally characterised by the absence of melanin pigments in the retinal epithelium of the central retina [29, 33]. Available evidence in other megachiropterans and pteropodids nevertheless show that bats of these clades contain retinal tapetum lucidum in the cells of the retinal epithelium $[8,29,31]$. The presence of reflective materials of the tapetum lucidum on an undulating surface is therefore a major and unique morphological adaptation for increased light sensitivity as each parabolic surface serves as a convex mirror, reflecting the light rays to the adjacent parabolic surface (Fig. 6). Photoreceptors associated with both papillae therefore get sensitised. This implies that a higher number of photoreceptors get sensitised in a megachiropteran eye than in a non-megachiropteran eye if both are exposed to the same incident light rays. it could also provide the much needed explanation why most megachiropterans are heavily reliant on their vison without the need for echolocation $[1,3,8,9,25,30]$ and why the relatively low mean corneal diameter to mean axial eye diameter ratio was observed in the fruit bat unlike the case in 
most nocturnal animals. It is, however, worth noting that the plane of orientation of the reflective materials of the tapetum in the retinal epithelium will influence the angle of reflection of the light rays. Thus, further investigations on the plane of orientation of these materials may be required to determine the angle of reflection.

\section{Acknowledgements}

The authors extend their appreciation to the Deanship of Scientific Research at King Khalid University for funding this work through Research Group Project under grant number (R.G.P.2/47/42).

\section{Conflict of interest: None declared}

\section{REFERENCES}

1. Aboelnour A, Noreldin AE, Massoud D, et al. Retinal characterization in the eyes of two bats endemic in the Egyptian fauna, the Egyptian fruit bat (Rousettus aegyptiacus) and insectivorous bat (Pipistrellus kuhlii), using the light microscope and transmission electron microscope. Microsc Res Tech. 2020; 83(11): 1391-1400, doi: 10.1002/jemt.23530, indexed in Pubmed: 33405350.

2. Agrawal RN, He S, Spee C, et al. In vivo models of proliferative vitreoretinopathy. Nat Protoc. 2007; 2(1): 67-77, doi: 10.1038/ nprot.2007.4, indexed in Pubmed: 17401340.

3. Cunhaalmeida F, Giannini N, Simmons N. The evolutionary history of the african fruit bats (Chiroptera: Pteropodidae). Acta Chiropterologica. 2016; 18(1): 73-90, doi: 10.3161/15081109a cc2016.18.1.003.

4. Aon MA, Curtino JA. Evidence for the glycoprotein nature of retina glycogen. Eur J Biochem. 1984; 140(3): 557-566, doi: 10.1111/ j.1432-1033.1984.tb08138.x, indexed in Pubmed: 6723649.

5. Aquino DA, Margolis RU, Margolis RK. Immunocytochemical localization of a chondroitin sulfate proteoglycan in nervous tissue. I. Adult brain, retina, and peripheral nerve. J Cell Biol. 1984; 99(3): 1117-1129, doi: 10.1083/jcb.99.3.1117, indexed in Pubmed: 6432802.

6. Bancroft JD, Layton C. Connective and mesenchymal tissues with their stains. In: Suvarna SK eds. 7th ed. Bancroft's Theory and Practice of Histological Techniques, Elsevier Ltd. 2013: 187-214.

7. Bancroft JD, Layton C. The hematoxylins and eosin. In: Suvarna SK eds. 7th ed. Bancroft's Theory and Practice of Histological Techniques, Elsevier Ltd. 2013: 172-186.

8. Bojarski C, Bernard R. Comparison of the morphology of the megachiropteran and microchiropteran eye. South African J Zool. 2015; 23(3): 155-160, doi: 10.1080/02541858.1988.11448095.

9. Brudenall DK, Schwab IR, Lloyd W, et al. Optimized architecture for nutrition in the avascular retina of Megachiroptera. Anat Histol Embryol. 2007; 36(5): 382-388, doi: 10.1111/j.14390264.2007.00779.x, indexed in Pubmed: 17845230.

10. Corfield JR, Gsell AC, Brunton D, et al. Anatomical specializations for nocturnality in a critically endangered parrot, the Kakapo (Strigops habroptilus). PLoS One. 2011; 6(8): e22945, doi: 10.1371/ journal.pone.0022945, indexed in Pubmed: 21860663.

11. El-Mansi AA, Al-Kahtani MA, Al-Sayyad KM, et al. Visual adaptability and retinal characterization of the Egyptian fruit bat (Rousettus aegyptiacus, Pteropodidae): New insights into photoreceptors spatial distribution and melanosomal activity. Micron. 2020; 137: 102897, doi: 10.1016/j.micron.2020.102897, indexed in Pubmed: 32563026.

12. Farina LL, Lankton JS. Chiroptera. Elsevier Inc. 2014

13. Fong SL, Liou GI, Landers RA, et al. Purification and characterization of a retinol-binding glycoprotein synthesized and secreted by bovine neural retina. J Biol Chem. 1984; 259(10): 6534-6542, doi: 10.1016/s0021-9258(20)82174-7.

14. Friend J, Kiorpes T, Kinoshita S. Glycogen and DNA content of corneal epithelium: comparison of preparation methods. Invest Ophthalmol Vis Sci. 1983; 24(2): 203-207, indexed in Pubmed: 6337970.
15. Gabriel LAR, Wang LW, Bader $H$, et al. ADAMTSL4, a secreted glycoprotein widely distributed in the eye, binds fibrillin-1 microfibrils and accelerates microfibril biogenesis. Invest Ophthalmol Vis Sci. 2012; 53(1): 461-469, doi: 10.1167/iovs.10-5955, indexed in Pubmed: 21989719.

16. Hall MI, Kamilar JM, Kirk EC. Eye shape and the nocturnal bottleneck of mammals. Proc Biol Sci. 2012; 279(1749): 4962-4968, doi: 10.1098/rspb.2012.2258, indexed in Pubmed: 23097513.

17. Hall MI. Comparative analysis of the size and shape of the lizard eye. Zoology (Jena). 2008; 111(1): 62-75, doi: 10.1016/j. zool.2007.04.003, indexed in Pubmed: 18054216.

18. Hall MI. The anatomical relationships between the avian eye, orbit and sclerotic ring: implications for inferring activity patterns in extinct birds. J Anat. 2008; 212(6): 781-794, doi: 10.1111/j.14697580.2008.00897.x, indexed in Pubmed: 18510506.

19. Hall MI, Ross CF. Eye shape and activity pattern in birds. J Zool. 2006; 271(4): 437-444, doi: 10.1111/j.1469-7998.2006.00227.x.

20. Inatani $\mathrm{M}$, Tanihara $\mathrm{H}$. Proteoglycans in retina. Prog Retin Eye Res. 2002; 21(5): 429-447, doi: 10.1016/s1350-9462(02)00009-5.

21. Inatani M, Tanihara H, Oohira A, et al. Upregulated expression of neurocan, a nervous tissue specific proteoglycan, in transient retinal ischemia. Invest Ophthalmol Vis Sci. 2000; 41(9): 2748-2754, indexed in Pubmed: 10937593.

22. Iwaniuk A, Heesy C, Hall M. Morphometrics of the eyes and orbits of the nocturnal Swallow-tailed Gull (Creagrus furcatus). Can J Zool. 2010; 88(9): 855-865, doi: 10.1139/z10-051.

23. Kirk EC. Comparative morphology of the eye in primates. Anat Rec A Discov Mol Cell Evol Biol. 2004; 281(1): 1095-1103, doi: 10.1002/ar.a.20115, indexed in Pubmed: 15470670.

24. Kuwabara T, Cogan DG. Retinal glycogen. Arch Ophthalmol. 1961; 59: 106-110, doi: 10.1001/archopht.1961.00960010682013. indexed in Pubmed: 14460992.

25. Kwiecinski G, Griffiths T. Rousettus egyptiacus. Mammalian Species. 1999(611): 1, doi: 10.2307/3504411.

26. Layton C, Bancroft JD. Carbohydrates. In: Suvarna SK eds. 7th ed. Bancroft's Theory and Practice of Histological Techniques., Elsevier Ltd. 2013: 215-238.

27. Magloire NCJ, Noel DD, Blaise K, et al. Spatiotemporal Activities of Eidolon helvum (Kerr, 1792 ) a Near-Threatened Species (Côte D'Ivoire, West Africa). Res Zool. 2018; 8(1): 6-11, doi: 10.5923/j. zoology.20180801.02.

28. Malinin GI, Bernstein $\mathrm{H}$. Histochemical demonstration of glycogen in corneal endothelium. Exp Eye Res. 1979; 28(4): 381-385, doi: 10.1016/0014-4835(79)90113-1, indexed in Pubmed: 446566 .

29. Ollivier FJ, Samuelson DA, Brooks DE, et al. Comparative morphology of the tapetum lucidum (among selected species). Vet Ophthalmol. 2004; 7(1): 11-22, doi: 10.1111/j.1463-5224.2004.00318.x indexed in Pubmed: 14738502.

30. Ossa G, Kramer-Schadt S, Peel AJ, et al. The movement ecology of the straw-colored fruit bat, Eidolon helvum, in sub-Saharan Africa assessed by stable isotope ratios. PLoS One. 2012; 7(9): e45729, doi: 10.1371/journal.pone.0045729, indexed in Pubmed: 23029206.

31. Pedler C, Tilley R. The retina of a fruit bat (Pteropus giganteus Brünnich). Vision Res. 1969; 9(8): 909-922, doi: 10.1016/00426989(69)90097-2, indexed in Pubmed: 5802397.

32. Peter-Ajuzie IK, Nwaogu IC, Ajaebili AC. Preliminary anatomical assessment of the eye of the African giant rat (Cricetomys gambianus). Agric Sci Dig. 2020; 40(01), doi: 10.18805/ag.d-183.

33. Peter-Ajuzıe I, Nwaogu I, Igwebuike U. Anatomical assessment of the eye of the african grasscutter (Thryonomys swinderianus). J Appl Life Sci Int. 2019: 1-8, doi: 10.9734/jalsi/2019/v20i230077.

34. Suthers RA. A comment on the role of choroidal papillae in the fruit bat retina. Vision Res. 1970; 10(9): 921-923, doi: 10.1016/00426989(70)90174-4, indexed in Pubmed: 5492784.

35. Tate DJ, Oliver PD, Miceli MV, et al. Age-dependent change in the hyaluronic acid content of the human chorioretinal complex. Arch Ophthalmol. 1993; 111(7): 963-967, doi: 10.1001/ archopht.1993.01090070083023, indexed in Pubmed: 8328939.

36. Wasilewa $\mathrm{P}$, Hockwin $\mathrm{O}$, Korte I. Glycogen concentration changes in retina, vitreous body and other eye tissues caused by disturbances of blood circulation. Albrecht Von Graefes Arch Klin Exp Ophthalmol. 1976; 199(2): 115-120, doi: 10.1007/BF02385207, indexed in Pubmed: 1083690. 